\title{
Surgical resection of primary tumors improved the prognosis of patients with bone metastasis of non-small cell lung cancer: a population-based and propensity score-matched study
}

\author{
Dan Tian ${ }^{1 \#}$, Xiaosong Ben ${ }^{1 \#}$, Sichao Wang ${ }^{1 \#}$, Weitao Zhuang ${ }^{1,2}$, Jiming Tang $^{1}$, Liang Xie ${ }^{1}$, Haiyu Zhou ${ }^{1}$, \\ Dongkun Zhang ${ }^{1}$, Zihao Zhou ${ }^{1}$, Ruiqing Shi ${ }^{1}$, Cheng Deng ${ }^{1}$, Yu Ding ${ }^{1,3}$, Xuanye Zhang ${ }^{4}$, Guibin Qiao ${ }^{1}$ \\ ${ }^{1}$ Department of Thoracic Surgery, Guangdong Provincial People's Hospital, Guangdong Academy of Medical Sciences, Guangzhou, China; ${ }^{2}$ Shantou \\ University Medical College, Shantou, China; ${ }^{3}$ The Second Clinical Medical School, Southern Medical University, Guangzhou, China; ${ }^{4}$ State Key \\ Laboratory of Oncology in South China, Collaborative Innovation Center for Cancer Medicine, Department of Medical Oncology, Sun Yat-sen \\ University Cancer Center, Guangzhou, China \\ Contributions: (I) Conception and design: D Tian, X Ben, S Wang, X Zhang, G Qiao; (II) Administrative support: G Qiao; (III) Provision of study \\ materials or patients: D Tian, X Ben, S Wang; (IV) Collection and assembly of data: All authors; (V) Data analysis and interpretation: All authors; (VI) \\ Manuscript writing: All authors; (VII) Final approval of manuscript: All authors. \\ \#These authors contributed equally to this work. \\ Correspondence to: Xuanye Zhang, MD. Department of medical oncology, Sun Yat-sen University Cancer Center, 651 Dongfeng East Road, Guangzhou \\ 510060, China. Email: zhangxuany@sysucc.org.cn; Guibin Qiao, MD, PhD. Department of Thoracic Surgery, Guangdong Provincial People’s Hospital, \\ Guangdong Academy of Medical Sciences, 106 Zhongshan Second Road, Guangzhou 510080, China. Email: guibinqiao@126.com.
}

Background: Most patients with lung cancer are in an advanced stage at the time of diagnosis due to occult onset. Bone is one of the most common sites of hematogenous metastasis of lung cancer. This study aimed to evaluate the impact of surgical resection of primary tumors on the prognosis of patients with bone metastasis of non-small cell lung cancer, using the Surveillance, Epidemiology, and End Results (SEER) database.

Methods: A total of 9,804 patients with only bone metastasis were identified from the SEER database. Propensity score matching was used to reduce the selection bias. Cancer-specific survival (CSS) and overall survival (OS) were compared between patients with or without primary tumor resection. The Cox regression model was applied to evaluate multiple prognostic factors.

Results: After propensity score matching, 424 patients were selected for survival analysis. No statistically significant differences were found in age, sex, race, tumor location, histology, T stage, and $\mathrm{N}$ stage between patients with or without surgical resection of primary tumors. The prognosis of patients who underwent surgical resection of primary tumors was significantly better than that of patients who had not undergone surgery. The surgical resection of primary tumors was an independent prognostic factor. The prognosis of patients who underwent lobectomy/bilobectomy was significantly better compared to other surgical types. Regional lymph node resection during surgery also significantly improved the prognosis of the patients.

Conclusions: For patients with only bone metastasis, surgical resection of primary tumors could significantly improve prognosis. Lobectomy/bilobectomy with regional lymph node resection was the best surgical strategy.

Keywords: Bone metastasis; non-small cell lung cancer; surgery; primary tumor; prognosis; Surveillance, Epidemiology, and End Results database

Submitted Jan 07, 2021. Accepted for publication Mar 05, 2021.

doi: $10.21037 / \mathrm{atm}-21-540$

View this article at: http://dx.doi.org/10.21037/atm-21-540 


\section{Introduction}

Lung cancer poses a serious threat to the lives and health of patients. Recent data showed that lung cancer had the second highest incidence and the highest mortality rate among all malignant tumors (1). Most of these patients are in an advanced stage at the time of diagnosis due to occult onset. The prognosis of patients is poor, and the overall 5 -year survival rate is only about $20 \%$ (2). Bone is one of the most common sites of hematogenous metastasis of lung cancer. Approximately $30 \%$ of patients with lung cancer had bone metastasis, and the spine and proximal end of the trunk bone were the most commonly involved sites (3). Most patients with bone metastasis developed skeletal-related events (SREs), such as pathological fracture and spinal cord nerve compression, which seriously affects the quality of life and survival time of patients.

Systemic therapy, such as targeted therapy and immunotherapy, combined with local therapy can effectively improve quality of life and prolong the survival time of patients with bone metastasis of lung cancer $(4,5)$. Typically, surgical resection of pulmonary lesions is not the initial treatment for these patients. Several retrospective studies suggested that the surgical resection of primary pulmonary lesions could significantly improve the prognosis of patients with distant metastasis of lung cancer (6-8). However, no study has investigated the impact of surgical resection of primary tumors on the prognosis of patients with bone metastasis. Therefore, in this study, the Surveillance, Epidemiology, and End Results (SEER) database was used to evaluate the prognosis of patients with only bone metastasis of non-small cell lung cancer after surgical resection of primary lung lesions, and to investigate the impact of different surgical methods on the prognosis of patients. We present the following article in accordance with the STROBE reporting checklist (available at http:// dx.doi.org/10.21037/atm-21-540).

\section{Methods}

\section{Patient selection and data extraction}

The SEER database provides information on cancer incidence and survival statistics in the United States (US) (9). The following databases were used for patient selection: SEER Program (www.seer.cancer.gov) SEER*Stat Database: Incidence-SEER 9 Regs Custom Data (with additional treatment fields), Nov 2018 Sub (1975-2016) <Katrina/Rita Population Adjustment>-Linked To County Attributes-
Total U.S., 1969-2017 Counties, National Cancer Institute, DCCPS, Surveillance Research Program, released April 2019, based on the November 2018 submission. Patients with a primary site of "lung and bronchus" were selected, while patients diagnosed through death certification or autopsy were excluded. As accurate information on distant metastasis sites was available only after 2010, the search period was restricted from 2010 to 2015. Data on "surgery of primary site" and "scope of regional lymph node surgery" were used to evaluate the detailed information on the surgical resection of primary tumors. Patients with brain metastasis, liver metastasis, lung metastasis, and unknown metastatic sites, patients with incomplete information records, and patients with "survival months $=0$ " or "tumor size $=0$ " were excluded. Patients' clinicopathological characteristics, such as age, sex, race, tumor location, histology, $\mathrm{T}$ stage, and $\mathrm{N}$ stage, were also extracted from the database. Cause-specific death, overall death classification, and survival months were used to calculate cancer-specific survival (CSS) and overall survival (OS).

The study was conducted in accordance with the Declaration of Helsinki (as revised in 2013).

\section{Statistical analyses}

SPSS version 23.0 (SPSS Inc., IL, USA) and Stata 15.0 (Stata Corp., TX, USA) software were used for statistical analyses. The propensity score was calculated by a logistic regression model using the following factors: age, sex, race, tumor location, histology, T stage, and $\mathrm{N}$ stage. Nearestneighbor matching without replacement was used, and the caliper was set to 0.02 . Propensity score matching (in a 1:1 manner) was performed using SPSS 23.0 software. The Pearson chi-squared $\left(\chi^{2}\right)$ test was used to identify the differences in categorical variables between the two groups. The two-sample $t$ test was used to determine the differences in continuous variables. The Kaplan-Meier method and the log-rank test were used to estimate the differences in survival between the groups. Multivariate analysis was performed using a Cox regression model to identify significant independent factors for survival between groups. A two-sided $P$ value of $<0.05$ was considered statistically significant.

\section{Results}

\section{Clinicopathological characteristics}

Between 2010 and 2015, 34,121 patients with bone metastasis 


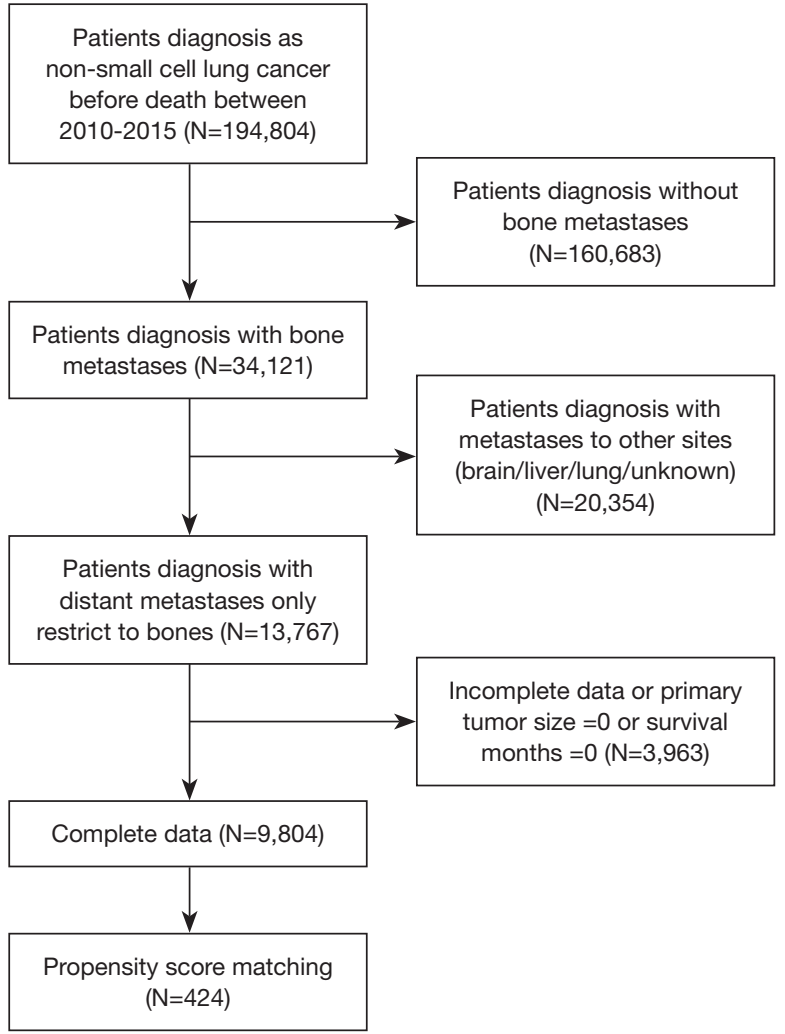

Figure 1 Flow diagram of patient selection.

were found in the SEER database. A total of 9,804 patients with bone metastasis were included in this study. Figure 1 shows the flow diagram of this study. The study comprised $5,735(58.5 \%)$ men and 4,069 (41.5\%) women, with a median age of 68.0 years. Furthermore, 7,737 patients (78.9\%) were white, $1,258(12.8 \%)$ were black, and 809 (8.3\%) belonged to other races in this study. Most of the tumors were located in the upper and middle lobes (59.6\%). Adenocarcinoma was the main histological type (59.2\%). According to the seventh edition of the TNM staging system, the study included, respectively, 1,639 cases (16.7\%), 3,279 cases (33.4\%), 2,374 cases $(24.2 \%)$, and 2,512 cases $(25.6 \%)$ of T1-T4, and 2,579 cases $(26.3 \%), 974$ cases (9.9\%), 4,508 cases (46.0\%), and 1,743 cases $(17.8 \%)$ of $\mathrm{N} 0-\mathrm{N} 3$. Of the 9,804 patients, $5,950(60.7 \%)$ received chemotherapy and 5,423 (55.3\%) received radiotherapy. Only 212 (2.2\%) patients underwent surgical resection of primary pulmonary tumors. Table 1 summarizes the clinicopathological data of the patients.

After the propensity score-matched analysis, 212 paired patients in both groups (with or without surgical resection of primary tumors) were matched. No statistically
Table 1 Clinicopathological characteristics of 9,804 patients with lung cancer with bone metastasis

\begin{tabular}{|c|c|}
\hline Characteristics & $\begin{array}{c}\text { Number of patients (\%) } \\
\text { or median value } \pm \text { SD }\end{array}$ \\
\hline Age & $68 \pm 11.14$ \\
\hline \multicolumn{2}{|l|}{ Sex } \\
\hline Male & $5,735(58.5)$ \\
\hline Female & $4,069(41.5)$ \\
\hline \multicolumn{2}{|l|}{ Race } \\
\hline White & 7,737 (78.9) \\
\hline Black & $1,258(12.8)$ \\
\hline Other & $809(8.3)$ \\
\hline \multicolumn{2}{|l|}{ Tumor location } \\
\hline Upper \& middle lobe & $5,843(59.6)$ \\
\hline Lower lobe & 2,641 (26.9) \\
\hline Other & $1,320(13.5)$ \\
\hline \multicolumn{2}{|l|}{ Histology } \\
\hline Adenocarcinoma & $5,806(59.2)$ \\
\hline Squamous cell carcinoma & $1,851(18.9)$ \\
\hline Other & 2,147 (21.9) \\
\hline \multicolumn{2}{|l|}{ T stage } \\
\hline $\mathrm{T} 1$ & $1,639(16.7)$ \\
\hline T2 & 3,279 (33.4) \\
\hline T3 & $2,374(24.2)$ \\
\hline $\mathrm{T} 4$ & $2,512(25.6)$ \\
\hline \multicolumn{2}{|l|}{$\mathrm{N}$ stage } \\
\hline No & $2,579(26.3)$ \\
\hline N1 & $974(9.9)$ \\
\hline N2 & $4,508(46.0)$ \\
\hline N3 & $1,743(17.8)$ \\
\hline \multicolumn{2}{|l|}{ Chemotherapy } \\
\hline Yes & $5,950(60.7)$ \\
\hline No & $3,854(39.3)$ \\
\hline \multicolumn{2}{|l|}{ Radiotherapy } \\
\hline Yes & $5,423(55.3)$ \\
\hline No & $4,381(44.7)$ \\
\hline \multicolumn{2}{|l|}{ Surgery for primary tumor } \\
\hline Yes & $212(2.2)$ \\
\hline No & $9,592(97.8)$ \\
\hline
\end{tabular}


significant differences were found in age, sex, race, tumor location, histology, $\mathrm{T}$ stage, and $\mathrm{N}$ stage between the two groups. Table 2 shows all the characteristics of the two paired groups.

\section{Survival analysis}

After the propensity score-matched analysis, 424 patients were included in the survival analysis. The prognosis of patients who underwent surgical resection of primary tumors was significantly better than that of patients who had not undergone surgery (5-year CSS rate, $24.3 \%$ vs. $4.8 \%$, $\mathrm{P}<0.001 ; 5$-year OS rate, $21.7 \%$ vs. $4.5 \%, \mathrm{P}<0.001$; Figure 2). The following clinicopathological features were included in the multivariate analysis: sex, age, race, tumor location, histology, T stage, $\mathrm{N}$ stage, chemotherapy, radiotherapy, and surgical resection of primary tumors. The results showed that sex (female $v s$. male), age ( $>63 v s . \leq 63$ years), $\mathrm{N}$ stage (N2-3 vs. N0-1), chemotherapy (yes vs. no), and surgical resection of the primary tumor (yes $v s$. no) were independent prognostic factors of CSS and OS in these patients (Table 3). The subgroup analysis showed that the surgical resection of primary tumors did not improve the prognosis of patients with T4 stage or N3 stage (Figure 3).

To further evaluate the effects of different surgical extension and lymph node resection on the prognosis of patients, 212 patients who underwent surgical treatment were selected for survival analysis. According to the surgical type, 96 patients underwent sublobar resection, 95 underwent lobectomy or bilobectomy, 11 underwent pneumonectomy, and 10 were unknown. According to the extent of the surgery, the survival analysis showed that the prognosis of patients who underwent lobectomy/bilobectomy was significantly better than that of other surgical types (5-year CSS rate, $37.0 \%$ vs. $12.8 \%, \mathrm{P}<0.001 ; 5$-year OS rate, $34.1 \%$ vs. $11.4 \%, \mathrm{P}<0.001$; Figure $4 A)$. In addition, 128 (60.4\%) patients underwent regional lymph node resection. The survival analysis showed that regional lymph node resection during surgery could significantly improve the prognosis of patients (5-year CSS rate, $31.5 \%$ vs. $12.2 \%, \mathrm{P}=0.003 ; 5$-year OS rate, $29.4 \%$ vs. $10.2 \%, \mathrm{P}<0.001$; Figure $4 B$ ). Furthermore, the prognosis of patients with lymph node dissection number $\geq 4$ was significantly better than that of other patients $(\mathrm{P}<0.001$ for CSS and OS; Figure 4C).

\section{Discussion}

This study was novel in investigating the significance of primary tumor resection in patients with simple bone metastasis. In this study, 9,804 patients were selected from the SEER database, and propensity score-matched analysis was used to systematically confirm that the surgical resection of primary pulmonary tumors could significantly improve the prognosis of patients with bone metastasis of non-small cell lung cancer. At the same time, the prognosis of patients who underwent lobectomy/bilobectomy was found to be significantly better than that of patients who underwent sublobar resection/pneumonectomy. Furthermore, the prognosis of patients with lymph node resection number $\geq 4$ was significantly better than that of patients who did not receive lymph node resection or who had lymph node resection number $<4$.

Surgical treatment for patients with advanced lung cancer remains controversial. Some retrospective studies have suggested that the surgical resection of primary tumors could significantly improve the prognosis of patients with brain metastasis of lung cancer. Bonnette et al. reported 103 patients with brain metastasis of non-small cell lung cancer who all underwent surgical resection of primary lung tumors within 4 months after surgical resection of brain lesions. The median survival of the patients was 12.4 months, and benefits were more obvious among patients with adenocarcinoma, small tumors, and nonlymph node metastasis (7). Sun et al. reported that primary tumor resection could improve survival in patients with extrathoracic metastatic non-small cell lung cancer (10). The results of a phase II, prospective, randomized, controlled study showed that for patients with oligometastasis of nonsmall cell lung cancer, local consolidation therapy (LCT), including surgery and radiotherapy, could effectively improve progression-free survival (PFS), which was 11.93 months in the LCT group and 3.9 months in the control group (11).

Bone is one of the most common sites for hematogenous metastasis. At present, the diagnosis of bone metastasis is mainly based on bone scan, but PET is considered to have higher sensitivity, specificity and lower false negative rate (12). Different types of bone metastases have the different adaptability of imaging methods. PET/CT has higher sensitivity and specificity for osteolytic changes or mixed lesions, but it is less sensitive and specific for osteoblastic changes (13). Imaging examination combined with tumor biomarker evaluation may improve the early detection rate of bone metastases. Considerable markers include crosslinked carboxy-terminal telopeptide of type I collagen (ICTP), amino-terminal collagen type I telopeptide 
Table 2 Clinicopathological characteristics of the two propensity score matched groups

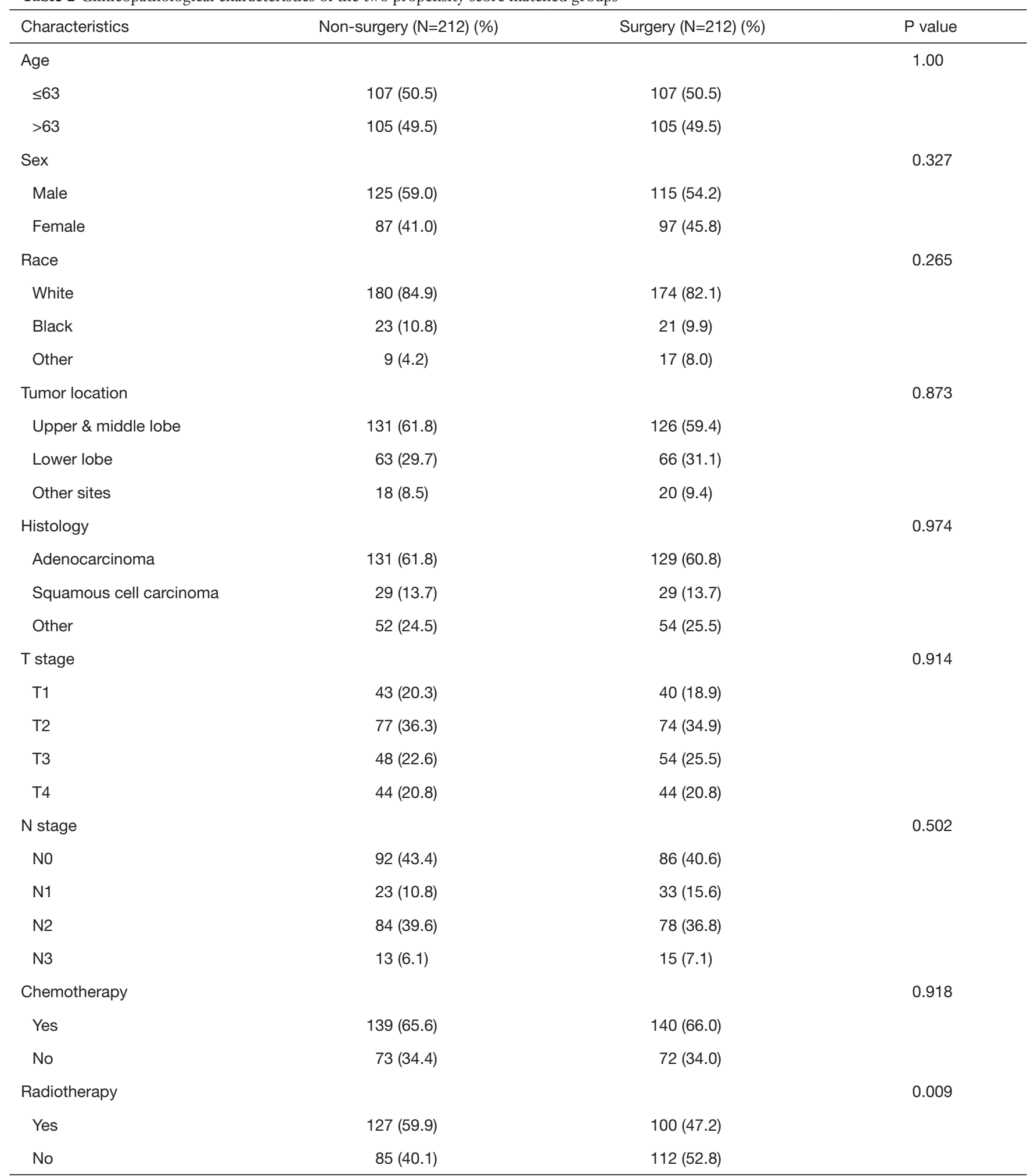



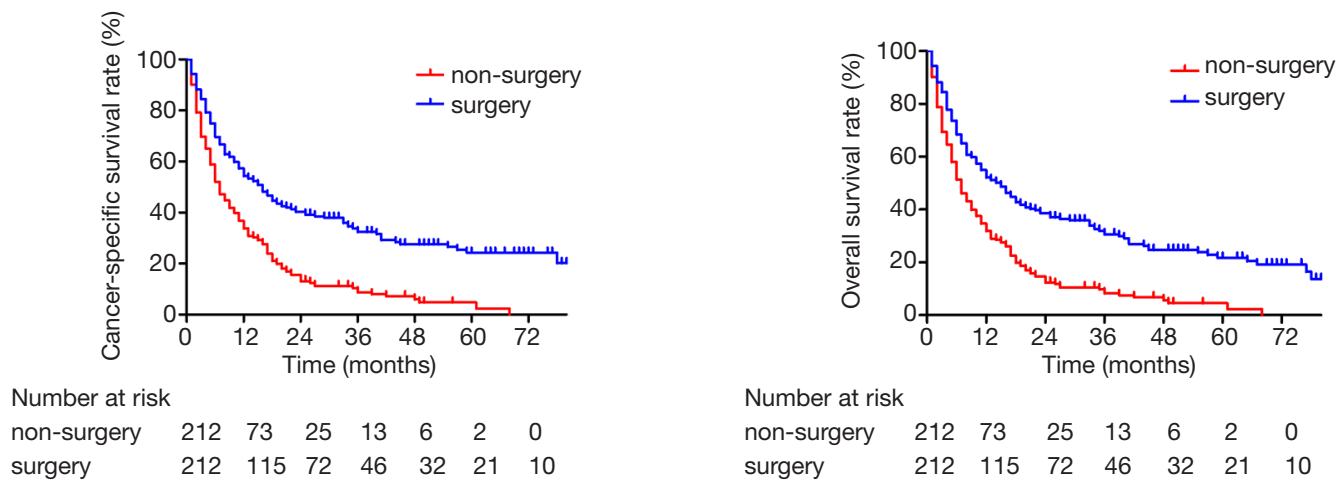

Figure 2 Kaplan-Meier curves of cancer-specific survival and overall survival of 424 patients. Blue: patients who underwent surgical resection of primary tumor. Red: patients who did not undergo surgical resection of primary tumor.

(NTX), tartrate-resistant acid phosphatase 5b (TRAP5b), bone alkaline phosphatase (BAP), and procollagen I amino-terminal propeptide (PINP). These markers can complement other diagnostic techniques and can also be used to assess the bone integrity and severity of bone metastases in patients at risk of metastasis (14). Typically, systemic treatment is the main choice for patients with bone metastasis. The impact of surgical treatment of the primary tumor is still inconclusive. Up to now, a few studies have explored the effect of surgical resection of primary tumors on the prognosis of patients with bone metastasis of non-small cell lung cancer. Distinct from other metastases, approximately $50 \%$ of patients with bone metastasis develop SREs. Once SREs occur, the survival time of patients is significantly shortened and their quality of life is greatly affected (3). Therefore, effectively controlling the development of bone metastasis and preventing the appearance of SREs are key to improving quality of life and prolonging the survival time of these patients.

The present study found that for patients with bone metastasis of non-small cell lung cancer, systemic chemotherapy was an independent prognostic risk factor, indicating that effective systemic treatment was still crucial for these patients. Contrastingly, radiotherapy did not improve the prognosis of patients. This was because, for some patients with bone metastases, local radiotherapy for metastases relieved only the symptoms of bone pain but did not delay the natural course of tumor development (15). The results also showed that only $2.2 \%$ of the patients underwent surgical resection of primary tumors, which was significantly lower than that of patients with brain metastasis. However, the prognosis of patients who underwent resection of primary tumors was significantly better than that of patients without surgical resection. The 5-year CSS and OS rates of patients who underwent resection were $24.3 \%$ and $21.7 \%$, respectively, which were much higher than those in the control group $(4.8 \%$ and $4.5 \%$, respectively). A previous study showed that for patients with oligometastasis of non-small cell lung cancer, the combination of systemic treatment and LCT could significantly delay the occurrence time of new tumor lesions (the median time of occurrence of new lesions for LCT vs. non-LCT: 11.9 vs. 5.7 months) (9). Circulating tumor cells (CTCs) are tumor cells that spread and survive in the blood circulation during the occurrence and development of malignant tumors. Studies have shown that CTCs can be detected in the peripheral blood of patients with advanced lung cancer, and the level of CTCs has a significant correlation with the stage and prognosis of patients $(16,17)$. Therefore, it is believed that the surgical resection of primary tumors can not only control the existing diseases, but also effectively reduce the tumor load and the continuous release of tumor cells into the circulatory system, thereby delaying the occurrence of new lesions and the progression of lung cancer, and prolonging the life of patients. Contrastingly, compared with liver metastasis, bone metastasis generally does not affect important organ functions. If the lesion can be effectively controlled, the survival time of patients can be significantly prolonged. In addition, in the era of precision medicine, targeted therapy and immunotherapy can significantly prolong the survival of patients with lung cancer. However, genotyping is needed to accurately screen the beneficiary population. The resected tumor can be used for molecular testing to provide guidance for the follow-up diagnosis and treatment of patients. However, it is suggested that not all patients 
Table 3 Multivariate analysis of cancer-specific survival and overall survival

\begin{tabular}{|c|c|c|c|c|c|c|}
\hline Factors & \multicolumn{3}{|c|}{ css } & \multicolumn{3}{|c|}{ OS } \\
\hline Sex & & & 0.002 & & & 0.001 \\
\hline Male & Reference & & & Reference & & \\
\hline Female & 0.698 & $0.556-0.875$ & & 0.693 & $0.556-0.863$ & \\
\hline$\leq 63$ & Reference & & & Reference & & \\
\hline$>63$ & 1.256 & $1.007-1.567$ & & 1.263 & $1.018-1.567$ & \\
\hline Race & & & 0.065 & & & 0.062 \\
\hline White & Reference & & & Reference & & \\
\hline Upper/middle/lower lobe & Reference & & & Reference & & \\
\hline Others & 0.873 & $0.591-1.288$ & & 0.847 & $0.578-1.242$ & \\
\hline Histology & & & 0.185 & & & 0.125 \\
\hline Adenocarcinoma & Reference & & & Reference & & \\
\hline Others & 1.169 & $0.928-1.474$ & & 1.193 & $0.953-1.493$ & \\
\hline T stage & & & 0.130 & & & 0.070 \\
\hline T1-2 & Reference & & & Reference & & \\
\hline T3-4 & 1.192 & $0.950-1.496$ & & 1.227 & $0.983-1.530$ & \\
\hline Yes & 0.475 & $0.375-0.601$ & & 0.477 & $0.379-0.600$ & \\
\hline Radiotherapy & & & 0.853 & & & 0.757 \\
\hline No & Reference & & & Reference & & \\
\hline Yes & 1.022 & $0.815-1.280$ & & 1.035 & $0.831-1.290$ & \\
\hline Surgical resection of primary tumor & & & $<0.001$ & & & $<0.001$ \\
\hline No & Reference & & & Reference & & \\
\hline Yes & 0.474 & $0.376-0.599$ & & 0.489 & $0.390-0.614$ & \\
\hline
\end{tabular}

CSS, cancer-specific survival; OS, overall survival; $\mathrm{HR}$, hazard ratio; $\mathrm{Cl}$, confidence interval.

with bone metastases can benefit from surgery. The results showed that the surgical resection of primary tumors did not prolong the survival of patients with $\mathrm{T} 4$ or $\mathrm{N} 3$ stage.
For these patients, surgical treatment is not recommended.

A previous clinical study showed that, compared with sublobar resection, lobectomy could effectively reduce 


\begin{tabular}{|c|c|c|c|c|c|}
\hline & Subgroup & $\begin{array}{l}\text { Cancer-specific survival } \\
\text { (surgery vs non-surgery) }\end{array}$ & Hazard ration & $95 \% \mathrm{Cl}$ & $P$ value \\
\hline \multirow[t]{2}{*}{ Sex } & Male & $\mapsto-1$ & 0.623 & $0.470-0.827$ & 0.001 \\
\hline & Female & $\mapsto-1$ & 0.391 & $0.272-0.562$ & $<0.001$ \\
\hline \multirow[t]{2}{*}{ Age } & Age $\leq 63$ & $\mapsto-1$ & 0.361 & $0.259-0.503$ & $<0.001$ \\
\hline & Age $>63$ & $\longmapsto$ & 0.676 & $0.500-0.915$ & 0.011 \\
\hline \multirow[t]{2}{*}{ Race } & White & $\mapsto-1$ & 0.547 & $0.430-0.695$ & $<0.001$ \\
\hline & Non-white & $\longmapsto$ & 0.326 & $0.178-0.597$ & $<0.001$ \\
\hline \multirow[t]{2}{*}{ Histology } & Adenocarcinoma & $\mapsto-1$ & 0.506 & $0.380-0.672$ & $<0.001$ \\
\hline & Non-adenocarcinoma & $\mapsto-1$ & 0.493 & $0.344-0.706$ & $<0.001$ \\
\hline \multirow[t]{4}{*}{ T stage } & $\mathrm{T} 1$ & $\longmapsto$ & 0.556 & $0.337-0.916$ & 0.021 \\
\hline & $\mathrm{T} 2$ & $\mapsto-1$ & 0.403 & $0.276-0.588$ & $<0.001$ \\
\hline & T3 & $\longmapsto$ & 0.468 & $0.294-0.744$ & 0.001 \\
\hline & T4 & $\longrightarrow$ & 0.765 & $0.476-1.229$ & 0.268 \\
\hline \multirow[t]{5}{*}{$\mathrm{N}$ stage } & No & $\mapsto-1$ & 0.419 & $0.289-0.608$ & $<0.001$ \\
\hline & N1 & $\longmapsto-1$ & 0.418 & $0.223-0.783$ & 0.006 \\
\hline & N2 & $\longmapsto \dashv$ & 0.561 & $0.399-0.788$ & 0.001 \\
\hline & N3 & $\longmapsto$ & 0.939 & $0.411-2.143$ & 0.881 \\
\hline & & $\begin{array}{ccc}1.0 & 1.5 & 2.0\end{array}$ & & & \\
\hline
\end{tabular}

\begin{tabular}{|c|c|c|c|c|c|}
\hline & Subgroup & $\begin{array}{c}\text { Overall survival } \\
\text { (surgery vs non-surgery) }\end{array}$ & Hazard ration & $95 \% \mathrm{Cl}$ & $P$ value \\
\hline \multirow[t]{2}{*}{ Sex } & Male & $\mapsto-1$ & 0.623 & $0.473-0.820$ & 0.001 \\
\hline & Female & $\mapsto-1$ & 0.420 & $0.295-0.599$ & $<0.001$ \\
\hline \multirow[t]{2}{*}{ Age } & Age $\leq 63$ & $\mapsto-1$ & 0.385 & $0.279-0.533$ & $<0.001$ \\
\hline & Age $>63$ & $\longmapsto+$ & 0.678 & $0.505-0.911$ & 0.010 \\
\hline \multirow[t]{2}{*}{ Race } & White & $\mapsto-1$ & 0.565 & $0.448-0.714$ & $<0.001$ \\
\hline & Non-white & $\longmapsto$ & 0.331 & $0.183-0.597$ & $<0.001$ \\
\hline \multirow[t]{2}{*}{ Histology } & Adenocarcinoma & $\mapsto-1$ & 0.525 & $0.397-0.693$ & $<0.001$ \\
\hline & Non-adenocarcinoma & $\mapsto$ & 0.504 & $0.356-0.714$ & $<0.001$ \\
\hline \multirow[t]{4}{*}{ T stage } & $\mathrm{T} 1$ & $\longmapsto$ & 0.563 & $0.343-0.925$ & 0.023 \\
\hline & $\mathrm{T} 2$ & $\mapsto-1$ & 0.426 & $0.295-0.616$ & $<0.001$ \\
\hline & $\mathrm{T} 3$ & $\longmapsto$ & 0.480 & $0.307-0.749$ & 0.001 \\
\hline & T4 & $\longmapsto$ & 0.750 & $0.471-1.194$ & 0.226 \\
\hline \multirow[t]{5}{*}{$\mathrm{N}$ stage } & No & $\mapsto-1$ & 0.455 & $0.318-0.652$ & $<0.001$ \\
\hline & N1 & $\longmapsto-$ & 0.411 & $0.223-0.759$ & 0.005 \\
\hline & N2 & $\mapsto-1$ & 0.568 & $0.407-0.793$ & 0.001 \\
\hline & N3 & $\longrightarrow$ & 0.913 & $0.414-2.016$ & 0.822 \\
\hline & & 2.0 & & & \\
\hline
\end{tabular}

Figure 3 Subgroup analysis for cancer-specific survival and overall survival in different patient subgroups stratified by sex, age, race, histology, T stage, and $\mathrm{N}$ stage. 
A

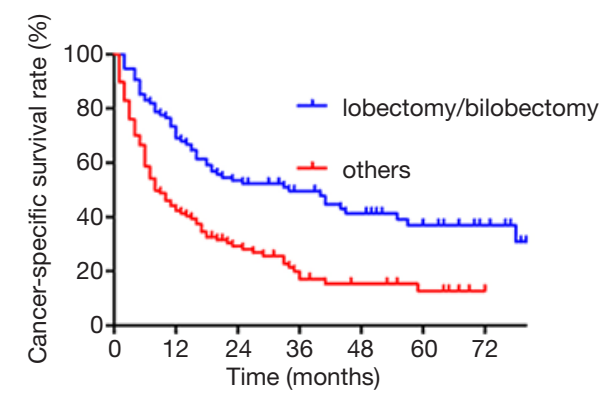

Number at risk

$\begin{array}{llllllll}\begin{array}{l}\text { lobectomy/ } \\ \text { bilobectomy } \\ \text { others }\end{array} & 95 & 68 & 47 & 32 & 24 & 16 & 9 \\ & 117 & 47 & 25 & 14 & 8 & 5 & 1\end{array}$

B

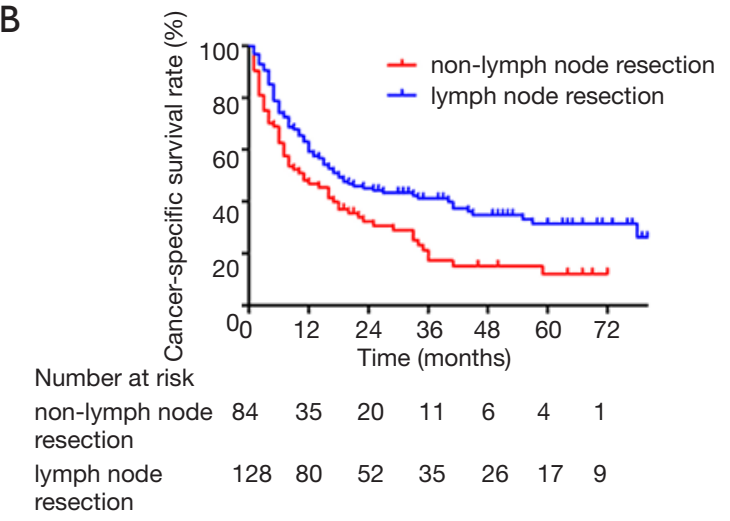

C

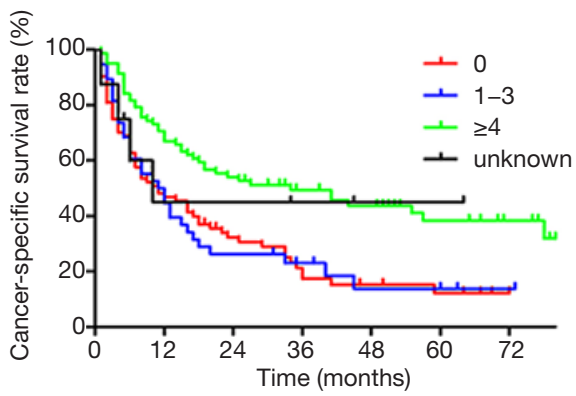

Number at risk

$\begin{array}{llllllll}0 & 84 & 35 & 20 & 11 & 6 & 4 & 1 \\ 1-3 & 38 & 19 & 9 & 6 & 3 & 3 & 1 \\ \geq 4 & 82 & 58 & 40 & 27 & 22 & 13 & 8 \\ \text { unknown } & 8 & 3 & 3 & 2 & 1 & 1 & 0\end{array}$

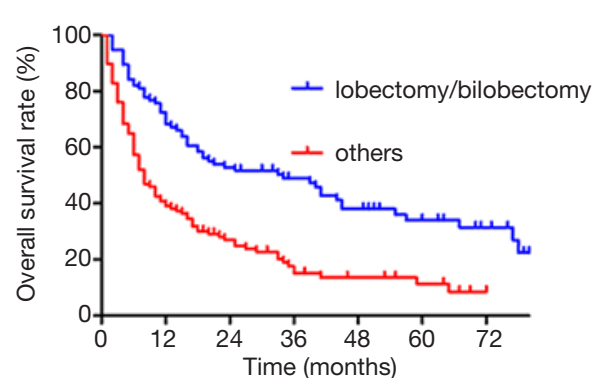

Number at risk

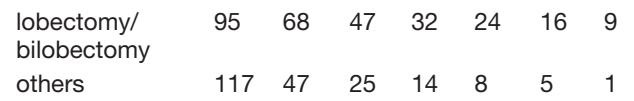

others

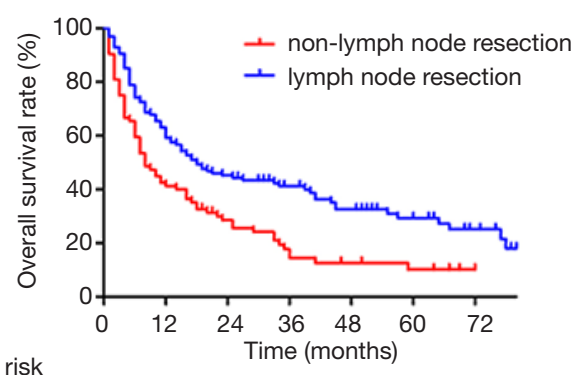

Number at risk

$\begin{array}{llllllll}\text { non-lymph node } & 84 & 35 & 20 & 11 & 6 & 4 & 1\end{array}$ resection

$\begin{array}{llllllll}\text { lymph node } & 128 & 80 & 52 & 35 & 26 & 17 & 9\end{array}$ resection

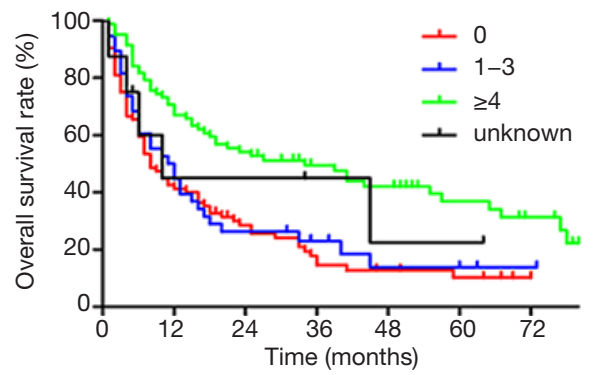

Figure 4 Kaplan-Meier curves of cancer-specific survival and overall survival of 212 patients who underwent surgical resection of primary tumor. (A) Blue: lobectomy/bilobectomy. Red: others. (B) Blue: lymph node resection. Red: non-lymph node resection. (C) Red: non-lymph node resection. Blue: number of lymph node resections 1 to 3 . Green: number of lymph node resections $\geq 4$. Black: number of lymph node resections unknown.

the risk of local recurrence and death for patients with early-stage non-small cell lung cancer (18). The present study found that lobectomy/bilobectomy was still the best surgical strategy for patients with bone metastasis of non-small cell lung cancer. Compared with sublobar resection, lobectomy could effectively remove the potential metastasis of pulmonary circulation and the lymphatic system, thus achieving radical resection. Furthermore, lobectomy/bilobectomy had a lower incidence of perioperative complications and mortality compared with 
pneumonectomy. For early-stage and locally advanced non-small cell lung cancer, intraoperative regional lymph node resection could significantly improve the prognosis of patients (19-21). The number of intraoperative lymph node resections has a significant correlation with the prognosis of patients $(22,23)$. The results showed that intraoperative regional lymph node resection could improve the prognosis of patients with bone metastasis. It was suggested that the number of lymph node resections should not be less than 4 . Systematic lymph node sampling/dissection could not only remove potential lymphatic metastases, but also make the $\mathrm{N}$ stage more accurate, thus providing a basis for subsequent treatment.

This study also found that for patients with bone metastasis of non-small cell lung cancer, the prognosis was worse in males and elderly patients. This result was similar to previous findings $(24,25)$. It was believed that the result might be related to the gene mutation status, overall treatment strategy, and therapeutic effect of the tumor, which need further exploration.

This study also had some limitations. First, being a retrospective study, inevitable selection bias was introduced in this study despite using propensity score-matched analysis to reduce the differences between the two groups. Second, only information on brain, liver, bone, and lung metastases was recorded, while data on other sites, such as the adrenal gland and abdominal cavity, were not available. Third, this study lacked accurate information on chemotherapy and radiotherapy, such as the regimen of chemotherapy and the dose and site of radiotherapy. Furthermore, the comprehensive treatment information on targeted therapy and immunotherapy was not obtained, and therefore the optimal treatment strategy for these patients could not be discussed. Finally, information related to bone metastasis, such as the accurate number and sites of bone metastasis, accompanying SREs, and LCT, was missing in the SEER database. Large-scale, randomized, controlled clinical trials are needed in the future to confirm the therapeutic effect of surgery on the bone metastasis of non-small cell lung cancer.

In conclusion, the surgical resection of primary tumors could significantly improve the prognosis of patients with only bone metastasis of non-small cell lung cancer. Lobectomy/bilobectomy with regional lymph node resection was the best surgical strategy.

\section{Acknowledgments}

Funding: None.

\section{Footnote}

Reporting Checklist: The authors have completed the STROBE reporting checklist. Available at http://dx.doi. org/10.21037/atm-21-540

Conflicts of Interest: All authors have completed the ICMJE uniform disclosure form (available at http://dx.doi. org/10.21037/atm-21-540). The authors have no conflicts of interest to declare.

Ethical Statement: The authors are accountable for all aspects of the work in ensuring that questions related to the accuracy or integrity of any part of the work are appropriately investigated and resolved. The study was conducted in accordance with the Declaration of Helsinki (as revised in 2013).

Open Access Statement: This is an Open Access article distributed in accordance with the Creative Commons Attribution-NonCommercial-NoDerivs 4.0 International License (CC BY-NC-ND 4.0), which permits the noncommercial replication and distribution of the article with the strict proviso that no changes or edits are made and the original work is properly cited (including links to both the formal publication through the relevant DOI and the license). See: https://creativecommons.org/licenses/by-nc-nd/4.0/.

\section{References}

1. Siegel RL, Miller KD, Jemal A. Cancer statistics, 2018. CA Cancer J Clin 2018;68:7-30.

2. Allemani C, Matsuda T, Di Carlo V, et al. Global surveillance of trends in cancer survival 2000-14 (CONCORD-3): analysis of individual records for 37 513025 patients diagnosed with one of 18 cancers from 322 population-based registries in 71 countries. Lancet 2018;391:1023-75.

3. Tsuya A, Kurata T, Tamura K, et al. Skeletal metastases in non-small cell lung cancer: a retrospective study. Lung Cancer 2007;57:229-32.

4. Bauml JM, Mick R, Ciunci C, et al. Pembrolizumab After Completion of Locally Ablative Therapy for Oligometastatic Non-Small Cell Lung Cancer: A Phase 2 Trial. JAMA Oncol 2019;5:1283-90.

5. Xu Q, Zhou F, Liu H, et al. Consolidative Local Ablative Therapy Improves the Survival of Patients With Synchronous Oligometastatic NSCLC Harboring EGFR 
Activating Mutation Treated With First-Line EGFRTKIs. J Thorac Oncol 2018;13:1383-92.

6. Billing PS, Miller DL, Allen MS, et al. Surgical treatment of primary lung cancer with synchronous brain metastases. J Thorac Cardiovasc Surg 2001;122:548-53.

7. Bonnette P, Puyo P, Gabriel C, et al. Surgical management of non-small cell lung cancer with synchronous brain metastases. Chest 2001;119:1469-75.

8. David EA, Andersen SW, Beckett LA, et al. Survival benefits associated with surgery for advanced nonsmall cell lung cancer. J Thorac Cardiovasc Surg 2019;157:1620-8.

9. Cronin KA, Ries LA, Edwards BK. The Surveillance, Epidemiology, and End Results (SEER) Program of the National Cancer Institute. Cancer 2014;120 Suppl 23:3755-7.

10. Sun Z, Sui X, Yang F, et al. Effects of primary tumor resection on the survival of patients with stage $I V$ extrathoracic metastatic non-small cell lung cancer: A population-based study. Lung Cancer 2019;129:98-106.

11. Gomez DR, Blumenschein GR Jr, Lee JJ, et al. Local consolidative therapy versus maintenance therapy or observation for patients with oligometastatic non-smallcell lung cancer without progression after first-line systemic therapy: a multicentre, randomised, controlled, phase 2 study. Lancet Oncol 2016;17:1672-82.

12. Qu X, Huang X, Yan W, et al. A meta-analysis of ${ }^{18} \mathrm{FDG}-$ PET-CT, ${ }^{18}$ FDG-PET, MRI and bone scintigraphy for diagnosis of bone metastases in patients with lung cancer. Eur J Radiol 2012;81:1007-15.

13. Nakamoto Y, Cohade C, Tatsumi M, et al. CT appearance of bone metastases detected with FDG PET as part of the same PET/CT examination. Radiology 2005;237:627-34.

14. Vicent S, Perurena N, Govindan R, et al. Bone metastases in lung cancer: potential novel approaches to therapy. Am J Respir Crit Care Med 2015;192:799.

15. De Felice F, Piccioli A, Musio D, et al. The role of radiation therapy in bone metastases management. Oncotarget 2017;8:25691-9.

16. Krebs MG, Sloane R, Priest L, et al. Evaluation and prognostic significance of circulating tumor cells in patients with non-small-cell lung cancer. J Clin Oncol 2011;29:1556-63.

17. Muinelo-Romay L, Vieito M, Abalo A, et al. Evaluation of Circulating Tumor Cells and Related Events as Prognostic Factors and Surrogate Biomarkers in Advanced NSCLC
Patients Receiving First-Line Systemic Treatment. Cancers 2014;6:153-65.

18. Ginsberg RJ, Rubinstein LV. Randomized trial of lobectomy versus limited resection for T1 N0 non-small cell lung cancer. Lung Cancer Study Group. Ann Thorac Surg 1995;60:615-22; discussion 622-13.

19. Keller SM, Adak S, Wagner H, et al. Mediastinal lymph node dissection improves survival in patients with stages II and IIIa non-small cell lung cancer. Eastern Cooperative Oncology Group. Ann Thorac Surg 2000;70:358-65; discussion 365-6.

20. Doddoli C, Aragon A, Barlesi F, et al. Does the extent of lymph node dissection influence outcome in patients with stage I non-small-cell lung cancer? Eur J Cardiothorac Surg 2005;27:680-5.

21. Meng D, Zhou Z, Wang Y, et al. Lymphadenectomy for clinical early-stage non-small-cell lung cancer: a systematic review and meta-analysis. Eur J Cardiothorac Surg 2016;50:597-604.

22. Gajra A, Newman N, Gamble GP, et al. Effect of number of lymph nodes sampled on outcome in patients with stage I non-small-cell lung cancer. J Clin Oncol 2003;21:1029-34.

23. Ding H, Wang H, Xu L, et al. Survival and resected lymph nodes number during sublobectomy for N0 NonSmall Cell Lung Cancer $</=2 \mathrm{~cm}$. Ann Thorac Surg 2019;107:1647-55.

24. Pagano E, Filippini C, Di Cuonzo D, et al. Factors affecting pattern of care and survival in a populationbased cohort of non-small-cell lung cancer incident cases. Cancer Epidemiol 2010;34:483-9.

25. Radkiewicz C, Dickman PW, Johansson ALV, et al. Sex and survival in non-small cell lung cancer: A nationwide cohort study. PLoS One 2019;14:e0219206.

(English Language Editor: C. Betlazar-Maseh)

Cite this article as: Tian D, Ben X, Wang S, Zhuang W, Tang J, Xie L, Zhou H, Zhang D, Zhou Z, Shi R, Deng C, Ding Y, Zhang X, Qiao G. Surgical resection of primary tumors improved the prognosis of patients with bone metastasis of non-small cell lung cancer: a populationbased and propensity score-matched study. Ann Transl Med 2021;9(9):775. doi: 10.21037/atm-21-540 